\title{
Adrian Mann appointed JMR Associate Editor, Biomaterials
}

I am very pleased to announce the appointment of Adrian Mann to the position of Associate Editor, Biomaterials. This position is newly created in response to strategic guidance and encouragement from the MRS Board of Directors to expand the topical coverage of $J M R$. While $J M R$ currently publishes biomaterials articles, I see the appointment of an expert Associate Editor in the field as the first step towards attracting a greater number and broader scope of materials science papers representing the diversity of topics covered in MRS biomaterials symposia and beyond. Prof. Mann's authority and responsibility will be to manage the peer review and decision process for manuscripts submitted as "Biomaterials Articles" using a group of Principal Editors who are experts in pertinent topics. The criteria for acceptance, as for all JMR papers, will be not only technical correctness but also a significant advance in the scientific understanding of or insight into the paper topic.

Professor Mann presently holds joint appointments at Rutgers University in the Department of Materials Science \& Engineering and the Department of Biomedical Engineering. Prior to Rutgers he was a lecturer in Biomedical Materials at the University of Manchester. Although his original research interests were on the nanomechanics of metallic and semiconductor thin films and surfaces, he has for many years focused on the nanomechanics of mineralized tissue and biological materials. Through his numerous research papers, contributed book chapters, and invited talks he has become recognized as an expert in the materials science of biomaterials. For the MRS Fall Meetings of 2001 and 2004 Prof. Mann was the lead organizer for symposia featuring biomaterialsrelated topics. The former was titled Physical Characterization of Biological Materials and Systems and the latter was Fundamentals of Nanoindentation \& Nanotribology III. Professor Mann has also been a JMR Principal Editor since 1997 and a special editor on two JMR focus issues, most recently the August 2006 focus issue on Mechanics of Biological and Biomimetic Materials at Small Length-Scales.

The editorial board and I look forward to working with Prof. Mann and we invite you to submit your biomaterials science manuscripts for publication in $J M R$.

Very truly yours,

Gordon Pike

Editor-in-Chief

DOI: $10.1557 / J M R .2006 .0328$ 